\title{
Structural characteristics of articular cartilage proteoglycan in IgG induced experimental immune synovitis
}

\author{
CHARLES J MALEMUD, ${ }^{12}$ JUNG U YOO,${ }^{3}$ VICTOR M GOLDBERG, ${ }^{3}$ \\ AND THOMAS F KRESINA ${ }^{1}$
}

From the Departments of ${ }^{1}$ Medicine, ${ }^{2}$ Developmental Genetics and Anatomy, and ${ }^{3}$ Orthopaedics, Case Western Reserve University School of Medicine, Cleveland, Ohio 44106, USA

\begin{abstract}
SUMmARY The early changes (five weeks) in the structure of newly synthesised and endogenousin articular cartilage sulphated proteoglycans were studied in lapine IgG induced experimentaF immune synovitis. Rabbits with immune synovitis (IS-IgG) were compared with animals with a developed hypersensitivity to IgG (I-IgG) and with non-treated normal weight matched controls.Medial and lateral femoral condyle and tibial plateau cartilage was pooled and radiolabelled for $24 \mathrm{~h}$ in vitro with ${ }^{35} \mathrm{SO}_{4}$. The samples constituted tissue from regions underlying pannus and from pannus free sites. Cartilage from animals with IS-IgG showed a significantly diminished amounto of newly synthesised and endogenous proteoglycan aggregate and an increased amount of hydrodynamically small proteoglycans. Newly synthesised (obtained by in vivo radiosulphateo labelling) and endogenous proteoglycans showed a similar profile. The proteoglycan monomers fraction from animals with IS-IgG failed to form proteoglycan aggregates in the presence of excess hyaluronic acid. In the group with IS-IgG linear regression analysis showed a statistically, significant relationship between the synovial pathology scores (but not cartilage pathology score) and diminished newly synthesised and endogenous proteoglycan aggregate.
\end{abstract}

Key word: rabbit.

The pathophysiological responses of articular cartilage accompanying synovial inflammation in rheumatoid arthritis remain unclear. Evidence has accumulated linking immunity to synovial joint extracellular matrix components in the pathogenesis of rheumatoid arthritis. For example, cell mediated immunity to genetically distinct collagens has been observed in classically defined rheumatoid arthritis, ${ }^{1-3}$ but a paucity of data exists with respect to proteoglycans. Recently, this laboratory has identified antibody to cartilage proteoglycan monomer in animals with experimentally induced immune synovitis (IS-IgG) ${ }^{4}$ and the presence of rheumatoid factor IgG and IgM antibodies in this animal model of arthritis (unpublished data).

Animal models of inflammatory arthritis have been studied to define more precisely the immune

Accepted for publication 20 February 1987.

Correspondence to Professor Charles J Malemud, Department of Medicine, Division of Rheumatic Diseases, Case Western Reserve University, Wearn Bldg. Rm. 549, Cleveland, Ohio 44106, USA. response to extracellular matrix components in? arthritis. The presumption is that the components of cartilage extracellular matrix exist, under norma占 conditions, in a sequestered state. Once released from cartilage, and provided that they are in a forms recognisable by immunocompetent cells, these com $\rightarrow$ ponents are capable of initiating cell mediated ans humoral immune responses. It is important to notw that the major portion of these extracellular matrix molecules comes from the already established struc 0 . turally stable cartilage matrix. Thus a tenet of this hypothesis is that enhanced release of extracellulap matrix components occurs as a consequence of locab joint disturbances involving cell communications, 5 monokine and lymphokine mediated activation, an synthesis of proteoglycanases and collagenaseo derived from synoviocytes and chondrocytes. ${ }^{7-11} \overline{0}$

The alterations in proteoglycan and collager? structure are not solely limited to areas of the्ष cartilage-pannus interface in inflammatory arthritis as erosions are frequently seen in pannus free areaş 
as well. ${ }^{12}$ In addition, compensatory synthesis repair of proteoglycans and collagen by the affected joint must also be considered in this regard, since marked structural alterations due to disease would result in their inability to become an established component of the cartilage extracellular matrix.

The present investigation studied early changes in newly synthesised and endogenous proteoglycans in a well established animal model of rheumatoid arthritis, which involves hyperimmunisation of rabbits with autologous IgG before intra-articular injection of IgG. ${ }^{13}$ The studies have been conducted under defined ex vivo short term explant culture conditions ${ }^{14}$ and compared with in vivo biosynthesis and alterations in the proteoglycan of articular cartilage.

\section{Materials and methods}

\section{R A B B I T S}

New Zealand White female virgin rabbits $(2-3 \mathrm{~kg})$ were obtained from the $\mathrm{H}$ and $\mathrm{E}$ rabbitry (Cleveland, $\mathrm{OH})$.

ANTIGEN

Rabbit IgG was purchased from Miles Laboratories Inc. (Elkhart, IN).

\section{IN DUCTION OF SYNOVITIS}

Antigen induced immune synovitis was produced by a modified method of Goldberg et al. ${ }^{13}$ Rabbits were primed subcutaneously (s.c.) with $4.0 \mathrm{mg}$ homologous rabbit IgG emulsified in Freund's complete adjuvant, boosted 1 week later with $2.0 \mathrm{mg}$ of IgG (s.c.) and 2 days later skin tested for reactivity to $\mathrm{IgG}$ and PPD. Only responding rabbits were used for induction of immune synovitis. During the subsequent 4 weeks, each rabbit received $1 \mathrm{mg} \mathrm{IgG}$ solubilized in $0.3 \mathrm{ml}$ saline, injected intra-articularly twice weekly into the left knee. Animals were killed after 5 weeks of intra-articular injection (ISIgG). Some rabbits with a defined hypersensitivity to IgG were injected intraarticularly with saline (IIgG). Weight matched non-treated animals served as a control group.

\section{PATHOLOGY SCORING}

A pathology score was derived by assigning equal weight to each of three parameters: cartilage, synovium and synovial fluid, as described previously. ${ }^{4}$ Where appropriate, bacterial cultures were established. All proved negative for bacterial growth.

EX VIVO SHORT TERM ORGAN CULTURE Immediately after sacrifice the articular cartilage from the medial and lateral femoral condyle and tibial plateau was pooled, and briefly incubated with testicular hyaluronidase. ${ }^{14}$ Minces of articular cartilage were incubated in Dulbecco's modified Eagle's medium (sulphate free) (Gibco, Grand Island, NY) containing $10 \%(\mathrm{v} / \mathrm{v})$ individually collected autologous rabbit sera as previously described. ${ }^{15}$ $\mathrm{Na}_{2}{ }^{35} \mathrm{SO}_{4}(370 \mathrm{kBq} / \mathrm{ml})$ (carrier free, ICN, Irvine, CA) was added for $24 \mathrm{~h}$.

\section{IN VIVO}

Twenty four hours before sacrifice, four normal, three I-IgG, and four IS-IgG rabbits were injected with ${ }^{35} \mathrm{SO}_{4}(27.8 \mathrm{MBq} / \mathrm{kg})$ through the marginal ear vein. ${ }^{16}$

PROTEOGLYCAN EXTRACTION

Articular cartilage minces were washed several times with saline. The tissue was extracted with $4 \mathrm{M}$ guanidine hydrochloride $/ 0 \cdot 1 \quad \mathrm{M}$ sodium acetate buffer, $\mathrm{pH} 5 \cdot 8$, containing a mixture of proteinase inhibitors, ${ }^{17}$ and, in addition, phenylmethane sulphonyl fluoride $(1 \mathrm{mM})$ for $24 \mathrm{~h}$ at $4^{\circ} \mathrm{C}$ with constant agitation. The extract was centrifuged and the supernatant dialysed exhaustively against double distilled deionized water $(\Omega=14)$ at $4^{\circ} \mathrm{C}$ for $48 \mathrm{~h}$. The retained fraction was freeze dried.

PROTEOGLYCAN EXTRACTION EFFICIENCY The pellet obtained by centrifugation of the cartilage extract was solubilised by digestion with papain followed by $\beta$ elimination with dilute alkali. ${ }^{15}$ The incorporated radioactivity and carbazole reactivity as a measure of uronic acid content ${ }^{18}$ were assayed on digested dialysed material. Proteoglycan extraction efficiency was calculated from the total incorporated ${ }^{35} \mathrm{SO}_{4}$ and uronic acid in the supernatant and the digested pellet.

PROTEOGLYCAN FRACTIONATION AND

CHROMATOGRAPHIC ANALYSES

The $4 \mathrm{M}$ guanidine hydrochloride $(\mathrm{GuHCl})$ extract was processed according to the scheme shown in Fig. 1. Equilibrium centrifugation ${ }^{19}$ under associative conditions (A) was performed in $\mathrm{CsCl}$ with 0.5 $\mathrm{M}$ guanidine hydrochloride $/ 0 \cdot 1 \mathrm{M}$ acetate buffer, $\mathrm{pH}$ 5.8. Under dissociative conditions (D) the buffer was $4 \mathrm{M}$ guanidine hydrochloride/ $0 \cdot 1 \mathrm{M}$ sodium acetate, $\mathrm{pH} 5 \cdot 8 .^{20}$ Proteoglycan aggregate fraction (dAl) was subjected to reduction/alkylation ${ }^{21}$ and chromatographed on Sepharose CL-2B.

STATISTICAL ANALYSIS

The statistical significance between group means was obtained from the Student's $t$ test $(\mathrm{p}<0 \cdot 05)$. A linear regression line was obtained by least squares 


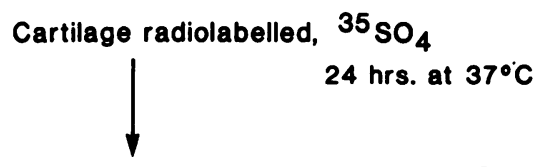

Tissue extracted $4 \mathrm{M}$ GuHCl/0.1M Sodium Acetate, $\mathrm{pH} 5.8+$ Proteinase Inhibitors $24 \mathrm{hrs}$. at $4^{\circ} \mathrm{C}$
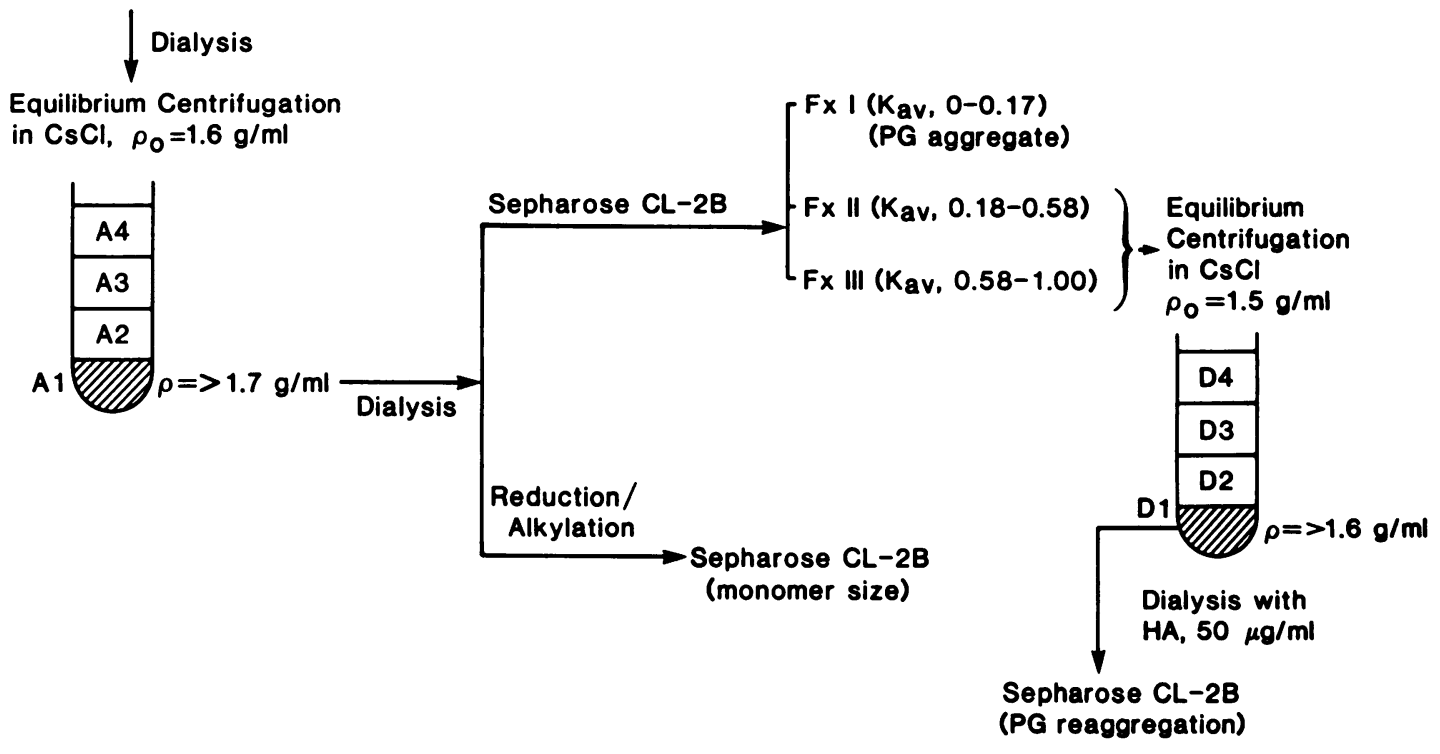

Fig. 1 Preparation of proteoglycan from rabbit articular cartilage under associative and dissociative conditions and chromatographic analyses.

analysis and the $t$ value calculated by the relationship $\mathrm{t}=\mathrm{r}-\mathrm{O} / \sqrt{\left(1-\mathrm{r}^{2}\right)(\mathrm{N}-2)}$ for values of $\mathrm{N}<30$.

\section{Results}

PROTEOGLYCAN EXTRACTION

The extraction efficiency of newly synthesised and endogenous proteoglycan was measured in control, I-IgG, and IS-IgG rabbits killed at five weeks. The total uronic acid content of IS-IgG articular cartilage extracted with $4 \mathrm{M}$ guanidine hydrochloride did not differ significantly from either normal or I-IgG animals (data not shown). The extraction efficiency of the newly synthesised proteoglycan from animals with IS-IgG was somewhat diminished (mean (SD); normal $89.7(2.0) \%$; I-IgG, $85.7(1.0)$; IS-IgG 79.2 $(2 \cdot 5) ; n=4)$, but the differences between the means did not reach statistical significance. Virtually identical amounts of endogenous proteoglycans as measured by uronic acid content were extracted from each group (normal $72.0(11.5) \%$; I-IgG 75 (4.0); IS-IgG $71 \cdot 5(15 \cdot 0)$.
DISTRIBUTION OF PROTEOGLYCAN IN ASSOCIATIVE CSCl DENSITY GRADIENTS The percentage of incorporated ${ }^{35} \mathrm{SO}_{4}$ in the most dense $\mathrm{dA} 1$ fraction of the three groups studied was the same. The dA1 fraction comprised $69 \cdot 2-75 \cdot 7 \%$ of the newly synthesised proteoglycan in animals with IS-IgG and $76 \cdot 7-78 \cdot 8 \%$ in controls. The percentage of endogenous proteoglycans reaching equilibrium in the $\mathrm{dA} 1$ fraction was somewhat diminished in the IS-IgG group $(55.9-65 \%)$ compared with the other groups $(74 \cdot 7-76 \cdot 4 \%)$.

GEL FILTRATION CHROMATOGRAPHY OF dA 1 FRACTIONS

The distribution of newly synthesised proteoglycan in the $\mathrm{dA} 1$ fraction in IS-IgG cartilage as measured by Sepharose CL-2B chromatography was different from that of either control group. There was a diminished amount of newly synthesised proteoglycan aggregate and an increase in the amount of newly synthesised hydrodynamically small proteoglycan subpopulation (fraction III) (Table 1). The endogenous proteoglycan also showed statistically 
Table 1 Distribution of newly synthesised and endogenous proteoglycan in fraction $d A I$ on Sepharose $C L-2 B$

\begin{tabular}{|c|c|c|c|}
\hline \multirow[t]{2}{*}{ Group } & \multicolumn{3}{|l|}{${ }^{35} \mathrm{SO}_{4}(\%)$} \\
\hline & Fraction I & Fraction II & Fraction III \\
\hline Normal $(n=6)$ & $16 \cdot 7(9 \cdot 6)$ & $61.5(14.5)$ & $20 \cdot()(13 \cdot 7)$ \\
\hline I-IgG $(n=3)$ & $15 \cdot 4(8 \cdot 5)$ & $55.3(16 \cdot 7)$ & $26 \cdot 8(25 \cdot 7)$ \\
\hline \multirow[t]{2}{*}{ IS-IgG $(n=9)$} & $4 \cdot 4(2 \cdot 6)^{*}$ & $54 \cdot 2(12 \cdot 1)$ & $38.1(10 \cdot 8) \div$ \\
\hline & \multicolumn{3}{|c|}{ Uronic acid $(\%)$} \\
\hline Normal & $29 \cdot 3(13 \cdot 0)$ & $43.7(10.9)$ & $27 \cdot 0(12 \cdot 1)$ \\
\hline I-IgG & $21 \cdot 0(14 \cdot 0)$ & 4()$\cdot()(2 \cdot 8)$ & $39 \cdot 0(17 \cdot 0)$ \\
\hline IS-IgG & $18 \cdot 4(5 \cdot 4) \div$ & $33.3(5.9) \div$ & $47 \cdot 4(9 \cdot 4)^{*}$ \\
\hline
\end{tabular}

Fraction $\mathrm{dAl}$ was prepared from a $4 \mathrm{M}$ guanidine hydrochloride extract of articular cartilage. An aliquot $(0.5 \mathrm{ml})$ of the fraction was applied to a column of Sepharose CL-2B $(0.4 \mathrm{~cm} \times 113 \mathrm{~cm})$ and eluted with $(0.5 \mathrm{M}$ sodium acetate buffer, pH 7. One millilitre fractions were collected. Column fractions corresponding to $K_{\text {in }}$ values of $0-() \cdot 17$ (fraction I), 0.18-0.57 (fraction II). and (0.58-1.0 (fraction III) were pooled. Recovery of radioactivity and uronic acid was as previously published. ${ }^{19}$

Values are mean $(\mathrm{SD}): \mathrm{n}=$ number of individual animals. ${ }^{*} \mathrm{p}<(0) \cdot(01 ; ; \mathrm{p}<0) \cdot(05$

significant differences between IS-IgG and control groups (Table 1). In addition to reduced quantities of proteoglycan aggregate, IS-IgG fraction $\mathrm{dA} 1$ showed a shift to subpopulations of smaller hydrodynamic size.

Reduction and alkylation of the $\mathrm{dA} 1$ fraction showed no differences among the groups in the hydrodynamic size of the proteoglycan monomer (Fig. 2). Neither the newly synthesised nor the endogenous proteoglycan monomer in the dAl fraction of IS-IgG cartilage was hydrodynamically smaller than either of the control groups.

\section{IN VIVO EXPERIMENTS}

We ascertained whether the changes in the distribution of proteoglycan in the dAl fraction of IS-IgG rabbit cartilage measured in ex vivo explant culture occurred in vivo as well. The amount of newly synthesised proteoglycan aggregate found in IS-IgG cartilage was significantly diminished (Table 2 ). In addition, there was a marked increase in the hydrodynamically small proteoglycan subpopulation (fraction III). No changes were seen in fraction II. Interestingly, these alterations were not found in the dAl fraction of cartilage derived from the contralateral knee of rabbits with IS-IgG (data not shown). This suggested that the change in elution profile of fraction $\mathrm{dAl}$ was limited to the pathologically affected knee.

FORMATION OF PROTEOGLYCAN

A GGREGATES

Proteoglycan monomer fractions (dD1) were pre-

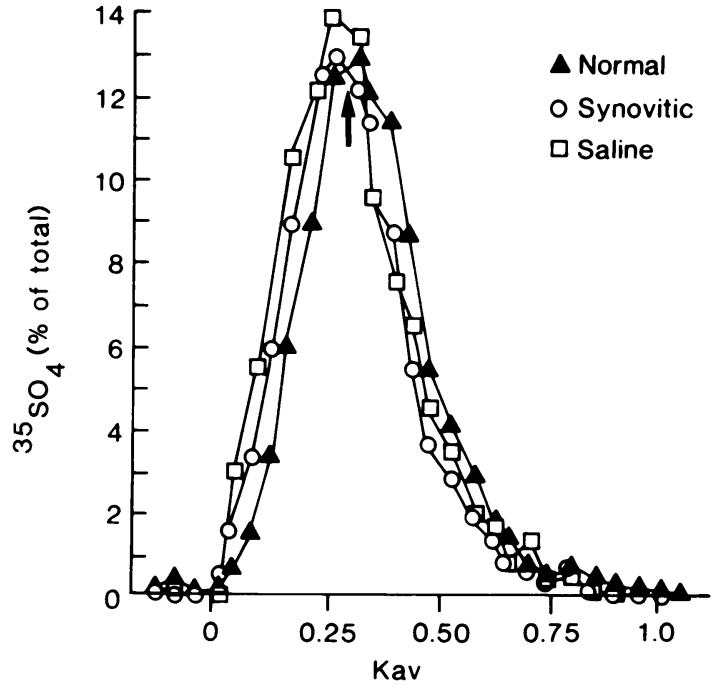

Fig. 2 Sepharose CL-2B chromatography of reduced and alkylated dAl fractions. Fraction dAl was chromatographed on Sepharose CL-2B and eluted with $0 \cdot 5 \mathrm{M}$ sodium acetate buffer, $\mathrm{pH} 7$, after reduction and alkylation. The $V_{o}\left(K_{a}=0\right)$ was obtained with bovine cartilage proteoglycan aggregate and the $V_{t}\left(K_{a v}=1\right)$ with $\mathrm{Na}_{2}{ }^{35} \mathrm{SO}_{4}$. The arrow indicates the peak elution fraction of endogenous hexuronic acid $\left(K_{a}=0 \cdot 35\right)$.

Table 2 Distribution of newly synthesised and endogenous proteoglycans in fraction $\mathrm{dAI}$ obtained after in vivo labelling with ${ }^{35} \mathrm{SO}_{4}$

\begin{tabular}{|c|c|c|c|}
\hline \multirow[t]{2}{*}{ Group } & \multicolumn{3}{|c|}{ Distribution (\%) } \\
\hline & Fraction I & Fraction II & Fraction III \\
\hline \multicolumn{4}{|l|}{ Normal $(n=4)$} \\
\hline${ }^{35} \mathrm{SO}_{4}$ & $22 \cdot 1(11 \cdot 2)$ & $35 \cdot 1(19 \cdot 3)$ & $37.9(24.4)$ \\
\hline Uronic acid & $39.5(14.5)$ & $35.5(13.5)$ & $25 \cdot 0(6 \cdot 5)$ \\
\hline \multicolumn{4}{|l|}{$I-\operatorname{IgG}(n=3)$} \\
\hline${ }^{35} \mathrm{SO}_{4}$ & $13 \cdot 8(6 \cdot 2)$ & $41 \cdot 8(22 \cdot 6)$ & $41 \cdot 5(28 \cdot 3)$ \\
\hline Uronic acid & $24.0(8.5)$ & $43 \cdot 0)(11 \cdot 0)$ & $33 \cdot()(10 \cdot 5)$ \\
\hline \multicolumn{4}{|l|}{ IS-IgG $(n=4)$} \\
\hline${ }^{35} \mathrm{SO}_{4}$ & $6 \cdot 7(2 \cdot 6)^{*}$ & $32 \cdot 6(16 \cdot 6)$ & $51.5(19.4)^{*}$ \\
\hline Uronic acid & $21 \cdot 3(5 \cdot 5)^{*}$ & $32.5(7 \cdot 0)$ & $45 \cdot 5(6 \cdot 0)^{*}$ \\
\hline
\end{tabular}

Fraction dAl was chromatographed on Sepharose CL-2B. Pooled fractions (see footnote to Table 1) were measured for radioactivity and carbazole reactivity.

Values are mean (SD).

${ }^{*} \mathrm{p}<0 \cdot 05$.

pared from pooled fraction II and fraction III after chromatography of dA1 fractions with Sepharose CL-2B. The contribution of the uronic acid from the exogenous hyaluronic acid was subtracted from the total carbazole reactivity to obtain the percentage of endogenous proteoglycan monomer that had formed proteoglycan aggregate. Approximately 
$82 \%$ of fraction II and $65 \%$ of fraction III reached equilibrium in the most dense fraction (dD1) after centrifugation. There were no differences between the groups. The endogenous proteoglycan monomer in fraction II formed proteoglycan aggregates which were decreased in the IS-IgG group (Table 3). Virtually none of the newly synthesised proteoglycan in fractions II or III formed proteoglycan aggregates.

CORRELATION OF GROSS PATHOLOGY AND ALTERATIONS IN PROTEOGLYCANS

The average pathology score of the combined femoral and tibial cartilage of the affected side was 2.94 in agreement with previously reported data in this model. ${ }^{13}$ The tibial score $(3 \cdot 11)$ was somewhat higher than the femoral score $(2 \cdot 78)$. There was a significant relationship between the pathology scores of the femur and the tibia $(r=0.85, p<0.01$, $n=9$ ). The pathology scores of the synovium and synovial fluid were in agreement with previously reported data. ${ }^{4}$ The combined score was $2 \cdot 44$. In contrast, the pathology score of normal control animals was zero; those of I-IgG and that of the contralateral knee of the IS-IgG group animals had an average score of 1 . The results of regression analysis showed that cartilage pathology scores did not reach a significant correlation with either the newly synthesised or endogenous proteoglycan aggregate (Figs $3 \mathrm{~A}$ and $\mathrm{B}$ ). In contrast, there was a

Table 3 Formation of proteoglycar aggregates

\begin{tabular}{lccc}
\hline Group & 2B & Fraction & Fraction I (\% \\
\hline Normal & II & ${ }^{35} \mathrm{SO}_{4}$ & $1 \cdot 4$ \\
& & Uronic acid & $25 \cdot 0$ \\
& III & ${ }^{35} \mathrm{SO}_{4}$ & $\mathrm{ND}$ \\
& & Uronic acid & $10 \cdot 0$ \\
I-IgG & II & $4 \cdot 5$ \\
& & ${ }^{35} \mathrm{SO}_{4}$ & $19 \cdot 0$ \\
& UII & $\mathrm{3} \mathrm{SO}_{4}$ & $\mathrm{ND}$ \\
& & Uronic acid & $12 \cdot 0$ \\
IS-IgG & II & $1 \cdot 1$ \\
& & $\mathrm{SO}_{4}$ & $5 \cdot 0$ \\
& III & ${ }^{35} \mathrm{SO}_{4}$ & $\mathrm{ND}$ \\
& & Uronic acid & $0 \cdot 0$ \\
& &
\end{tabular}

A protcoglycan monomer fraction (dD1) was generated from pooled eluates of fraction II and fraction III ( see footnote to Table 1) by density gradient ultracentrifugation in $\mathrm{CsCl}$ in dissociative buffer (4 M guanidine hydrochloride). The $\mathrm{dD} 1$ fractions were dialysed and freeze dried. The freeze dried sample was dissolved in $0.5 \mathrm{M}$ sodium acetate buffer, $\mathrm{pH} 7$, and dialysed with umbilical cord hyaluronic acid against sodium acetate buffer at $4^{\circ} \mathrm{C}$ for $24 \mathrm{~h}$. An aliquot of this sample was chromatographed on Sepharose CL-2B and the radioactivity and carbazole reactivity of pooled fraction I assayed. Bovine nasal proteoglycan aggregate (A1) was used to calculate the $V_{0}$ of the column.

$\mathrm{ND}=$ not determined because radioactivity was at background levels $(<15 \mathrm{cpm})$.
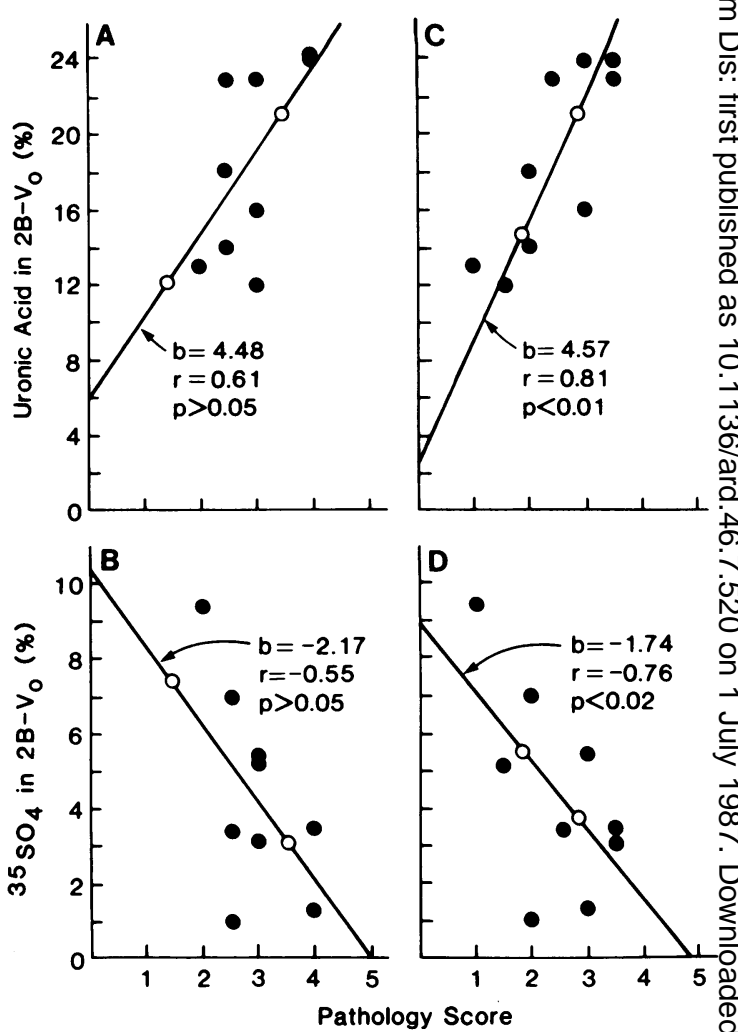

Fig. 3 Regression analysis determining the strength of correlation of pathology scores with newly synthesised and endogenous proteoglycan aggregate in fraction $\mathrm{dAI}$. The linear regression line $\left(\mathrm{O}_{-}\right)$was obtained by least squares analysis. $(A)$ Cartilage score $v$ endogenous proteoglycan aggregate; $(B)$ cartilage score $v$ newly synthesised proteoglycan aggregate; $(C)$ synovium score (synovium + synovial fluid) $v$ endogenous proteoglycan aggregate; (D) synovium score $v$ newly synthesised proteoglycan aggregate.

statistically significant relationship between diminution of proteoglycan aggregate and the pathology score of the synovium (Figs 3C and D)

\section{Discussion}

The destruction of articular cartilage and underlying subchondral bone is a hallmark of inflammator\% arthritis. Depletion of cartilage extracellular matrios components occurs aggressively, mediated in part b* enzymatic dissolution of proteoglycan and collagen. ${ }^{2}$ In chronic forms of synovitis, activators of chondrocyte proteinases secreted by inflammator $\dot{\phi}$ synovia are believed to have a central role in the final common pathway of joint damage. ${ }^{11} 22$ 
Compensatory synthesis of cartilage proteoglycans occurs in articular cartilage in response to trauma and enzymatic depletion of the pericellular matrix. ${ }^{23}$ Noteworthy is recent evidence that catabolin (interleukin 1) and proteolytic enzymes, such as elastase, not only enhance proteoglycan catabolism but also suppress proteoglycan synthesis. ${ }^{24} 25$

The results of this investigation indicated that the structure of the existing proteoglycan was altered as expected. The newly synthesised proteoglycan, however, was also affected as characterised by a reduction in the amount of proteoglycan aggregated to hyaluronic acid, and by the increased synthesis of hydrodynamically small proteoglycans.

The amount of proteoglycan aggregate was significantly diminished in the affected IS-IgG cartilage. Interestingly, the differences obtained in this study between control and IS-IgG rabbits were similar to those reported by Oegema and Behrens, who compared normal rabbits with rabbits chronically administered hydrocortisone. ${ }^{26}$ They found that in control animals $17 \cdot 1 \%$ of the hexuronic acid and $10.7 \%$ of the incorporated ${ }^{35} \mathrm{SO}_{4}$ was in the proteoglycan aggregate subpopulation; this was reduced to $6.3 \%$ and $5.4 \%$ in animals treated with hydrocortisone.

The finding that the proteoglycan monomer generated by reduction and alkylation of the proteoglycan aggregate fraction did not differ among the three groups was unexpected. Thus proteoglycan monomer in the IS-IgG group that interacted with cartilage hyaluronic acid appeared to be protected from multiple cleavages in the chondroitin sulphate attachment region of the proteoglycan monomer, a finding recently supported by the data of Campbell et al. ${ }^{27}$

The amount of the hydrodynamically small proteoglycan subpopulation (fraction III) was significantly increased in IS-IgG cartilage. Its origins are unknown at present. It is conceivable that it represents, in part, a degradation product of fraction II. In that case its quantitative increase in IS-IgG may have resulted from either synovial or cartilage proteinases. ${ }^{28-31}$

Alternatively, small chondroitin sulphate proteoglycans have been reported as endogenous subpopulations of hyaline cartilage ${ }^{32}$ and as a specific low molecular weight synthesis product of articular chondrocytes. ${ }^{33}$ The fact that $62 \%$ of fraction III reached equilibrium with the most dense $\mathrm{CsCl}$ density gradient fraction suggests that shortened or undersulphated glycosaminoglycan chains are not likely to be an important characteristic of the small hydrodynamic size of this proteoglycan subpopulation.

The pathology score of the synovium indicated that it could be reasonably used to predict the extent of damage to the endogenous proteoglycan aggregate. In that respect, synovial inflammation reported to occur after repeated intra-articular saline injections ${ }^{34}$ may have been responsible for the slight decrease in fraction I in I-IgG animals. The negative slope obtained when synovial pathology scores were correlated with newly synthesised proteoglycan aggregate (Fig. 3D) indicated that low pathology scores are associated with a statistically significant smaller amount of newly synthesised proteoglycan aggregate than would normally be predicted.

Finally, these results argue persuasively that the synovium has a major role in the proteoglycan changes in IS-IgG. The fact that altered patterns of newly synthesised proteoglycan could be measured ex vivo suggests that factors secreted by synovium and affecting proteoglycans may also be recovered from the rabbit sera.

Heightened release of proteoglycan or its fragments from the tissue under these conditions is presumably responsible for the raised antiproteoglycan antibody titres measured in the serum of animals with IS-IgG. ${ }^{+}$

Supported by NIH grants, AG-(02205. A M-20618, and AM-075(05 and a grant from the Orthopacdic Research and Education Foundation.

\section{References}

1 Trentham D E. Dynesius R A. Rocklin R E. David J R. Cellular sensitivity to collagen in rheumatoid arathritis. $N$ Engl J Med 1978; 299: 327-32.

2 Endler A T, Zielinski C. Menzel E. et al. Leukocyte migration inhibition with collagen type I and collagen type III in rheumatoid arthritis and degenerative joint diseases. $Z$ Rheumatol 1978: 37: 87-92.

3 Stuart J M. Postlethwaite A E. Kang A H. Townes A S. Cellmediated immunity to collagen in rheumatoid arthritis [Abstract| Arthritis Rheum 1979: 22: 665.

4 Yoo J U. Kresina T F. Malemud C J. Goldberg V M. Epitopes of proteoglycans eliciting an anti-proteoglycan response in chronic immunc synovitis. Proc Natl Acad Sci USA 1987; 84: 832-6.

5 Barrett A J. The enzymic degradation of cartilage matrix. In: Burleigh P M C. Poole A R. eds. Dynamics of connective tissue macromolecules. Amsterdam: North Holland. 1975: 189-215.

6 Fell $\mathrm{H} \mathrm{B}$. Jubb $\mathrm{R}$ W. The effect of synovial tissue on the breakdown of articular cartilage in organ culture. Arthritis Rheum 1977: 20: 1359-71.

7 Wood D D, Ihric E J. Dinarello C A. Cohen P I. Isolation of interleukin-1-like factor from human joint effusions. Arthritis Rheum 1983; 26: 975-83.

8 Ridge S C. Oronsky A L. Kerwar S S. Induction of synthesis of latent collagenase and latent neutral protease in chondrocytes by a factor synthesized by activated macrophages. Arthritis Rheum 1980; 23: 448-54.

9 McGuire-Goldring M B. Meats J E. Wood D D. Ihric E J. Ebsworth N M. Russell R G G. In vitro activation of human chondrocytes and synoviocytes by a human interleukin-1-like factor. Arthritis Rheum 1984: 27: 654-62.

10 Gowen M. Wood D D. Ihrie E J. Meats J E, Russell R G G. Stimulation by human interleukin- 1 of cartilage breakdown and 
production of collagenase and proteoglycanase by human chondrocytes but not by human osteoblasts in vitro. Biochim Biophys Acta 1984: 797: 186-93.

11 Saklatvala J. Characterization of catabolin, the major product of pig synovial tissue that induces resorption of cartilage proteoglycan in vitro. Biochem J 1981: 199: 705-14.

12 Cooke T D V. Sumi M. Maeda M. Deleterious interactions of immune complexes in cartilage of experimental immune arthritis. I. The erosion of pannus-free cartilage. Clin Orthop 1985; 183: $225-45$.

1.3 Goldberg V M. Lance E M. Davies P. Experimental immune synovitis in the rabbit. Relative roles of cell-mediated and humoral immunity. Arthritis Rheum 1974: 17: 993-1005.

14 Malemud C J, Norby D P. Sokoloff L. Explant culture of human and rabbit articular chondrocytes. Connect Tissue Res 1978; 6: 171-9.

15 Srivastava V M L. Malemud C J. Sokoloff L. Chondroid expression by lapine articular chondrocytes in spinner culture following monolayer growth. Connect Tissue Res 1974: 2: 127-36.

16 Malemud C J. Janoff A. Identification of neutral proteases in human neutrophil granules that degrade articular cartilage proteoglycan. Arthritis Rheum 1975: 18: 361-8.

17 Oegema T R Jr. Hascall V C. Dziewiatkowski D D. Isolation and characterization of proteoglycans from the Swarm rat chondrosarcoma. J Biol Chem 1975: 250: 6151-9.

18 Bitter T. Muir H. A modified uronic acid carbazole reaction. Anal Biochem 1962: 4: 33(1-4.

19 Malemud C J. Goldberg V M. Moskowitz R W. Getzy L L. Papay R S. Norby D P. Biosynthesis of proteoglycan in vitro by cartilage from human osteochondrophytic spurs. Biochem $J$ 1982: 206: 329-41.

20) Malemud C J. Shuckett R. Papay R S. Mills T M. Goldberg $\mathrm{V} M$. In vitro culture of human and lapine articular chondrocytes: a reliable system for the study of sulphated-proteoglycan biosynthesis. In: Verbruggen G. Veys E M. eds. Degenerative joints. Vol 2. Amsterdam: Elsevier, 1985: 211-22.

21 Heinegård D. Axelsson I. Distribution of keratan sulfate in cartilage proteoglycans. J Biol Chem 1977: 252: 1971-9.

22 Dingle J T. Saklatvala J, Hembry R. Tyler J. Fell H B, Jubb R. A cartilage catabolic factor from synovium. Biochem J 1979; 184: $177-80$
23 Mankin $\mathrm{H} J$. The reaction of articular cartilage to injury an ostcoarthritis. N Engl J Med 1974; 291: 1285-92, 1335-40. क?

24 Bartholomew J S. Lowther D A. Handley C J. Changes i proteoglycan biosynthesis following leukocyte clastase treate ment of bovine articular cartilage in culture. Arthritis Rheur 1984: 27: $9(05-12$.

25 Dingle J T. The effect of synovial catabolin on cartilage synthetic activity. Connect Tissue Res 1984: 12: 277-86.

26 Oegema T R Jr. Behrens F. Proteoglycan aggregate synthesis if normal and chronically hydrocortisone-suppressed rabbit articular cartilage. Arch Biochem Biophys 1981: 206: 277-840

27 Campbell I K. Roughley P J, Mort J S. The action of humaß articular cartilage metalloproteinase on proteoglycan and link protein. Similarities between products of degradation in situ and in vitro. Biochem $J$ 1986; 237: 117-22.

28 Pelletier J-P. Martel-Pelletier J. Malemud C J. Proteoglycand from canine articular cartilage: a comparison between norma and osteoarthritic knees. Trans Orthop Res Soc 1986; 11: 230

29 Malemud C J. Norby D P. Moskowitz R W. Goldberg V MO Sapolsky A I. Howell D S. Neutral proteinases from articular chondrocytes in culture that degrade synthetic substrates ans cartilage macromolecules. Semin Arthritis Rheum 1981; 19 (suppl): 61-3.

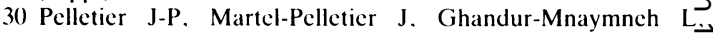
Howell D S. Woessner J F Jr. Role of synovial membrane inflammation in cartilage collagen matrix breakdown in the Pond-Nuki dog model of osteoarthritis. Arthritis Rheum 1985. 28: $554-61$.

31 Steinberg J J, Hubbard J. Sledge C B. In vitro models 99 cartilage degradation and repair. In: Otterness I, Lewis A, Capetola R, eds. Therapeutic control of inflammatory diseases advances in inflammation research. Vol 11. New York: Rave Press, 1986: 215-41.

32 Heinegård D, Paulsson $\mathrm{M}$, Incrot S, Carlstrom C. A novel lo molecular chondroitin sulphate proteoglycan isolated from cartilage. Biochem J 1981; 197: 355-66.

33 Vittur F, Dumontier M-F. Stagni N. Corvol M. In vitro biosynthesis by articular chondrocytes of a specific low moleciō lar size proteoglycan pool. FEBS Lett 1983; 153: 187-93.

34 Frost L, Ghosh P. Microinjury to the synovial membrane ma政 cause disaggregation of proteoglycans in rabbit knee joirt articular cartilage. J Orthop Res 1984; 2: 207-20. 